\author{
А. А. Слепых, аспирант \\ И. И. Коршиков, д.б.н, проф. \\ Донецкий ботанический сад НАН Украины, ул. Маршака, 50, г. Кривой Рог, \\ 50089, Украина

\section{ПЛОДОНОШЕНИЕ ДУБА ЧЕРЕШЧАТОГО (QUERCUS ROBUR L.) И ФОРМОВОЕ РАЗНООБРАЗИЕ ЖЕЛУДЕЙ В ПРИРОДНЫХ И ИССКУСТВЕННЫХ ДУБРАВАХ ЮГО-ВОСТОКА УКРАИНЫ}

\begin{abstract}
Исследовано плодоношение и формовое разнообразие желудей $Q$. robur в 7-ми заповедных территориях Донецкой области в насаждениях с обильной, хорошей и удовлетворительной урожайностью. Межурожайный период у дубрав региона составляли 2-3 года. Определена изменчивость морфологических параметров плодов и плюски Q. robur, которая колебалась в диапазоне 8-16 \%. Масса плодов варьировала в пределах 30-45 \%. В дубравах преобладали растения с типичной формой желудей и средней их крупностью. Выделены древостои, в которых доминировали растения с длинноплодной и широкоокруглой формой желудя. По фенологическим наблюдениям, дубравы исследуемого региона разделены на 2 группы: раннюю и позднюю. Отмечено, что ранняя форма $Q$. robur более приурочена к пойменным экотипам и имеет лучшие показатели массы желудей и урожайности.
\end{abstract}

Ключевые слова: Засушливость; произрастание; фенологическая форма; изменчивость; урожайность; крупность плода; коэффициент формы плода.

Одним из основных видов деревьев - эдификаторов широколиственной, лесостепной и степной зон Восточной Европы является дуб черешчатый - Quercus robur L. $[1,6]$. В последние десятилетия в большей или меньшей степени отмечена деградация и массовое усыхание дубрав во многих европейских странах $[15,31,32]$. Причины этого явления исследователями объясняются по-разному. Преобладающая гипотеза - синергетическое действие вредных абиотических и биотических факторов: глобальные изменения климата; загрязнение окружающей среды; поражённость дубрав вредными насекомыми и патогенами $[21,24]$.

На пределе естественного распространения Q. robur в Донецкой области отмечено усыхание дубрав, вызванное недостатком влаги, вредителями и болезнями, избыточной рекреационной нагрузкой и несоблюдением правил лесоводственного ухода $[22,25]$. Восстановление дубрав зачастую протекало очень сложно, как правило, с большими техническими просчётами и экономическими потерями. На первых этапах это объяснялось недостаточными знаниями биологии дуба и технологии выращивания дубрав в засушливых условиях. 
Из-за высокого светолюбия подроста [2] для Q. robur характерно неудовлетворительное возобновление под пологом широколиственных лесов, на что обращали внимание разные исследователи [3; 4]. По мере становления цикличномозаической концепции развития экосистем было высказано предположение, что неустойчивое естественное возобновление $Q$. robur связано с отсутствием в современных широколиственных лесах «окон» бездревесных растений большого размера [5]. Несмотря на наличие таковых «окон» в дубравах Степной зоны Украины, процессы естественного возобновления Q. robur в них замедляются $[20,23,27,28]$. Неудовлетворительное возобновление дубрав связано, в первую очередь, с недостаточностью в них высококачественных желудей [8, $13,14,16]$. В ряде исследований показано, что рост молодых растений зависит от размера формы и массы желудей $[5,6,7,10,12,13,18]$.

При искусственном возобновлении дубрав особое место отводится подбору посадочного материала, отличающегося формовым разнообразием $[7,10]$.

Цель исследования - анализ морфометрических параметров, плодоношения, урожайности и формового разнообразия желудей $Q$. robur, произрастающих на 7-ми объектах ПЗФ в Донецкой области.

\section{Материалы и методы исследований}

Исследование проводили на желудях популяций $Q$. robur, произрастающих в 7-ми объектах природно-заповедного фонда Донецкой области. Из них - 5 местопроизрастаний - это байрачные дубравы естественного происхождения в РЛП «Донецкий кряж», НПП «Святые горы», заповедник «Меловая флора», РЛП «Клебан-бык», РЛП «Краматорский» (участок «Белокузьминовский») и 2 - это лесные заказники искусственного происхождения «Великоанадольский лес» (посадки проведены в 1845-1900-х г.) [22] и «Азовская дача» (дубовые насаждения на высоком плато юга области, посадки выполнены в начале XX-го века) (рис. 1).

В каждой из семи дубрав, для исследований отбиралось 40-60 деревьев генеративного возраста, занимающих площадь от 0,5 до 1,1 га, а с каждого дерева собирали по 40-50 штук желудей. Сборы плодов осуществлялись в сентябре-октябре в период 2014-2016 г. У желудей с помощью штангенциркуля измеряли длину (L) и диаметр желудя (Ø), а также длину (l), высоту (h) и глубину плюски (Ø) (рис. 2). После флотации и удаления воды с поверхности желудей [12], они взвешивались на аналитических весах 2-го класса. Желуди группировали по формам и размерам (табл. 1). Фенологические наблюдения за цветением и формированием листьев проводили в течении 3-х лет.

Оценка цветения и плодоношения производилась по шестибальной шкале В. Г. Каппера (от 0 до 5) [33]. 


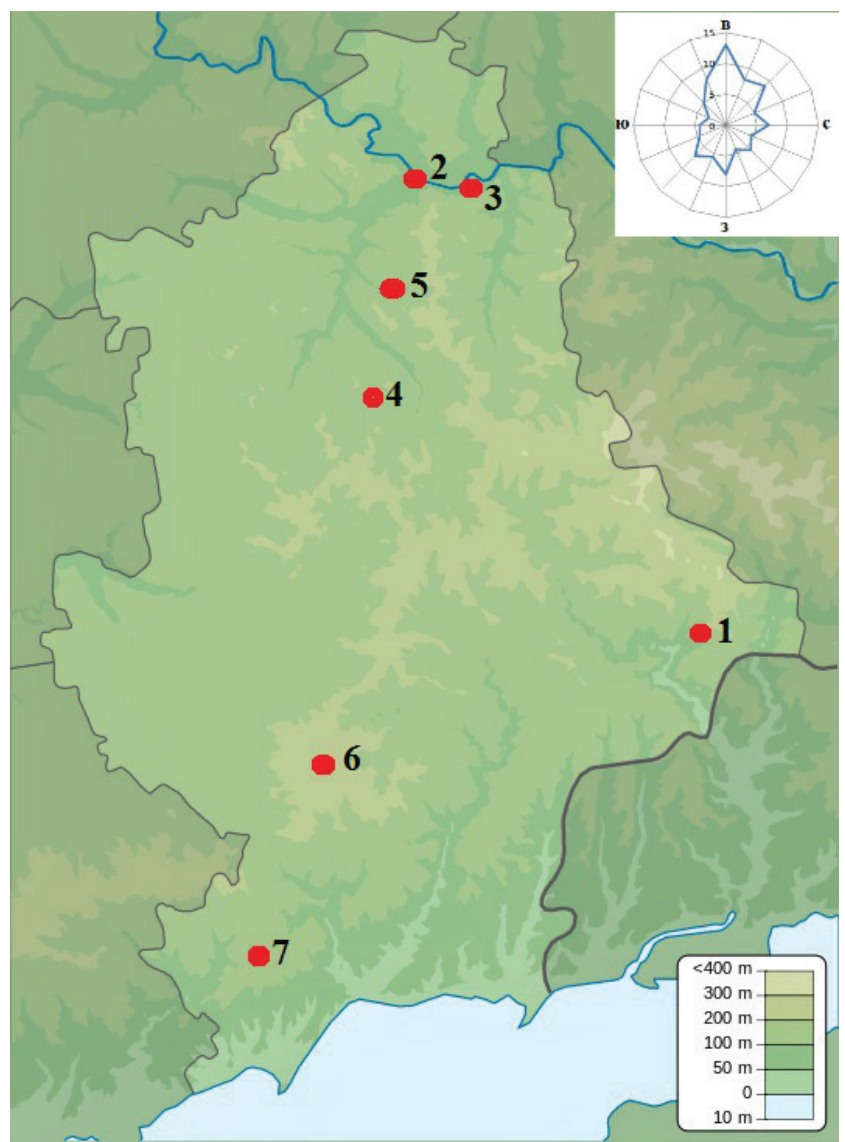

1 - РЛП «Донецкий

кряж»

2 - НПП «Святые горы»

3 - Заповедник «Меловая флора»

4 - РЛП «Клебан-бык»

5 - РЛП «Краматорский»

6 - Заказник «Великоана-

дольский лес»

7 - Заказник «Азовская

дача»

Puc. 1. Карта-схема районов исследования в Донеикой области
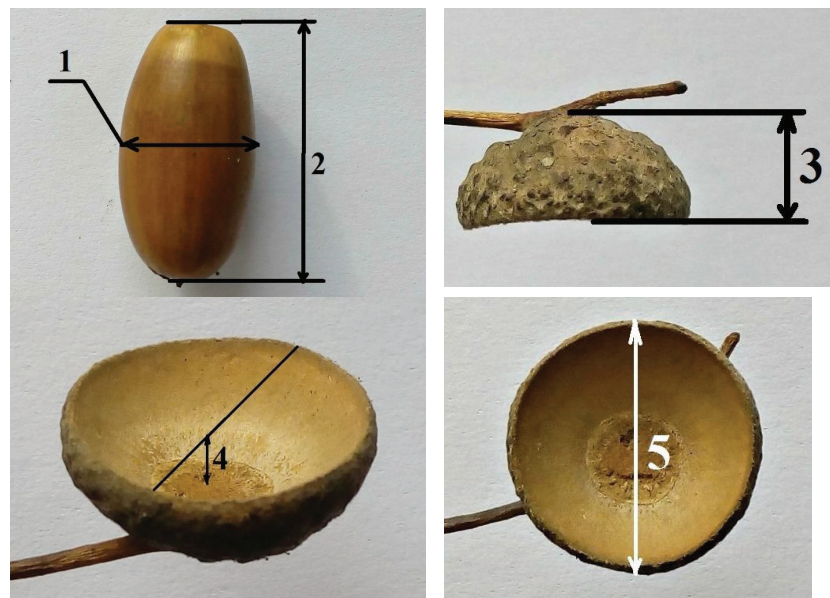

Рис. 2. Схема измеряемых параметров желудя и плюски

Примечание: 1 - Ø желудя; 2 - L желудя; 3 - 1 плюски; 4 - h плюски;5 - Ø плюски 
Таблица 1

Распределение желудей $Q$. robur по форме и размерам

\begin{tabular}{|c|c|c|c|c|}
\hline \multirow[b]{2}{*}{ Форма плодов } & \multirow{2}{*}{$\begin{array}{c}\text { Средний коэф- } \\
\text { фициент формы } \\
\text { (по А. С. Яков- } \\
\text { леву [24]) } \\
\end{array}$} & \multirow{2}{*}{$\begin{array}{l}\text { Классифика- } \\
\text { ция плодов } \\
\text { по массе }\end{array}$} & \multicolumn{2}{|c|}{ Средняя масса желудя, г } \\
\hline & & & $\begin{array}{c}\text { По М. Д. Данилову } \\
\text { [7] } \\
\end{array}$ & $\begin{array}{c}\text { По Д. Г. Гурьеву } \\
{[10]} \\
\end{array}$ \\
\hline Длиноплодные & 2,01 и выше & $\begin{array}{c}\text { Мелкоплод- } \\
\text { ные }\end{array}$ & до 2,0 & до 3,0 \\
\hline Типичные & от 1,51 до 2,0 & $\begin{array}{c}\text { Среднеплод- } \\
\text { ные }\end{array}$ & от 2,1 до 4,0 & от 3,1 до 5,0 \\
\hline Широкоокруглые & до 1,50 & $\begin{array}{c}\text { Крупноплод- } \\
\text { ные }\end{array}$ & 4,1 более & 5,1 и более \\
\hline
\end{tabular}

Соответствие балов: 0 - цветения и плодоношения нет; 1 - очень слабое цветение или очень плохое плодоношение (цветы, шишки или плоды в небольшом количестве на деревьях, растущих по опушкам, и на единично стоящих деревьях; в ничтожных количествах в насаждениях); 2 - слабое цветение или слабое плодоношение (наблюдается довольно удовлетворительное и равномерное цветение или плодоношение на свободно стоящих деревьях, растущих по опушкам (слабое насаждение)); 3 - среднее цветение или среднее плодоношение (довольно значительное цветение и плодоношение на деревьях, растущих по опушкам, и на свободно стоящих деревьях; удовлетворительное - в средневозрастных и спелых насаждениях); 4 - хорошее цветение или хорошее плодоношение (обильное цветение или плодоношение на деревьях, растущих по опушкам, и на свободно стоящих деревьях; хорошее - в средневозрастных и спелых насаждениях); 5 - очень хорошее цветение или очень хорошее плодоношение (обильное плодоношение на деревьях, растущих по опушкам, и на свободно стоящих деревьях, а также в средневозрастных и спелых насаждениях). Урожайность определяли по шкале урожайности лиственных пород И. И. Раца [11], где оценка осуществлялась по количеству плодов, посчитанному на 1 м $^{2}$ модельного дерева. Для обильного урожая их количество составляло более 25 шт., хорошего 13-25 шт., удовлетворительного - 5-12 шт. Фенологические фазы развития описывали согласно рекомендациям Н. Е. Булыгина [26], путем учета дат последовательного наступления фенологических фаз [35] на постоянных и временных пробных площадях районов исследований.

Обработку данных производили с помощью программ STATISTICA 10 и Microsoft Excel.

\section{Результаты исследований и обсуждение}

Трехлетние наблюдения за сезонным развитием растений в дубравах показали, что в Донецкой области четко выделяются две фенологические формы Q. robur: рано- (p, Quercus robur L. f. praecox Czern.) и позднецветущая (п, Quercus robur L. f. tardiflora Czern.) (табл. 2). Как правило, ранняя форма 
Q. robur в этом регионе приурочена к поймам рек, произрастает на низинных ландшафтах - Приднепровской и Приазовской низменности. Для поздней формы свойственны дубравы, локализированные на возвышенных элементах ландшафтах - преимущественно на Донецком кряже [35].

Таблица 2

Результаты фенологических наблюдений за цветением и распусканием листьев дуба черешчатого $Q$. robur, 2014-2016 гг.

\begin{tabular}{|c|c|c|c|c|}
\hline \multirow{2}{*}{ Год } & \multirow{2}{*}{ Пробная площадь } & \multicolumn{2}{|c|}{ Дата прохождения фенофазы } & \multirow{2}{*}{$\begin{array}{c}\text { Продолжительность } \\
\text { фенофазы, } \\
\text { дней }\end{array}$} \\
\hline & & $\begin{array}{c}\text { Начало } \\
\text { (Апрель) }\end{array}$ & $\begin{array}{l}\text { Окончание } \\
\text { (Май) }\end{array}$ & \\
\hline \multirow{7}{*}{2014} & РЛП «Донецкий кряж» (п) & 25 & 15 & 21 \\
\hline & НПП «Святые горы» (р) & 6 & 2 & 27 \\
\hline & Заповедник «Меловая флора» (р) & 7 & 1 & 25 \\
\hline & РЛП «Клебан-бык» (п) & 23 & 10 & 18 \\
\hline & РЛП «Краматорский» (п) & 19 & 9 & 21 \\
\hline & $\begin{array}{l}\text { заказник «Великоанадольский } \\
\text { лес» (п) }\end{array}$ & 20 & 19 & 30 \\
\hline & заказник «Азовская дача» (п) & 20 & 17 & 28 \\
\hline \multirow{7}{*}{2015} & РЛП «Донецкий кряж» (п) & 28 & 20 & 23 \\
\hline & НПП «Святые горы» (р) & 10 & 10 & 31 \\
\hline & Заповедник «Меловая флора» (р) & 10 & 8 & 29 \\
\hline & РЛП «Клебан-бык» (п) & 25 & 16 & 22 \\
\hline & РЛП «Краматорский» (п) & 22 & 17 & 26 \\
\hline & $\begin{array}{l}\text { заказник «Великоанадольский } \\
\text { лес» (п) }\end{array}$ & 26 & 27 & 32 \\
\hline & заказник «Азовская дача» (п) & 27 & 25 & 29 \\
\hline \multirow{7}{*}{2016} & РЛП «Донецкий кряж» (п) & 29 & 22 & 24 \\
\hline & НПП «Святые горы» (p) & 5 & 7 & 33 \\
\hline & Заповедник «Меловая флора» (р) & 7 & 6 & 30 \\
\hline & РЛП «Клебан-бык» (п) & 28 & 20 & 23 \\
\hline & РЛП «Краматорский» (п) & 16 & 16 & 32 \\
\hline & $\begin{array}{l}\text { заказник «Великоанадольский } \\
\text { лес» (п) }\end{array}$ & 30 & 30 & 31 \\
\hline & заказник «Азовская дача» (п) & 30 & 31 & 32 \\
\hline
\end{tabular}


Из полученных данных наблюдений видно, что в заповеднике «Меловая флора» и НПП «Святые горы» доминирует раноцветущая форма. В остальных пяти районах произрастания преобладает поздняя форма. Возможно, эти фенологические различия $Q$. robur связаны с контрастностью эдафических условий, так как раноцветущая форма произрастает на меловых почвах, которые отсутствуют в пяти других местообитаниях дуба.

Различия в фенологии $Q$. robur в пределах одного и того же местопроизрастания по годам объясняются флуктуациями погодных условий на начало вегетационного периода. В одном случае, как правило, наблюдается стремительное потепление (по наблюдениям 2014 г. и 2016 г., [35]), а в другом - сопряжено с возвратом холодов и заморозков (по наблюдениям 2015 г. [35]) [7, 19, 35].

На основе собранного урожая желудей в 2016 г., проведен анализ их морфологической изменчивости и плюсок на кронах модельных деревьев $Q$. robur (табл. 3). Установлено, что разным параметрам свойственен свой определенный уровень изменчивости, который сохраняет относительное постоянство во всех 7-ми районах произрастания Q. robur в Донецкой области. Наибольшей изменчивостью характеризуются длина и высота плюски и длина желудя $(\mathrm{CV}=9$ 16 \%). Менее изменчивый диаметр плюсок и желудей $(\mathrm{CV}=6,5-9 \%$ \%).

Таблица 3

Морфологическая изменчивость желудей и их плюсок в древостоях Quercus robur Донецкой области, 2016 г.

\begin{tabular}{|c|c|c|c|c|}
\hline Параметр & $\begin{array}{c}\text { Количество } \\
\text { модельных } \\
\text { деревьев, шт. }\end{array}$ & $\begin{array}{c}\text { Лимиты } \\
\text { абсолютных величин, } \\
\text { мм }\end{array}$ & $\begin{array}{c}\text { Среднее } \\
\text { значение, мм }\end{array}$ & $\begin{array}{c}\text { Коэффициент } \\
\text { вариации, \% }\end{array}$ \\
\hline 1 & 2 & 3 & 4 & 5 \\
\hline \multicolumn{5}{|c|}{ РЛП «Донецкий кряж» (естественная популяция) } \\
\hline L желудя & \multirow{5}{*}{53} & $23-32$ & $28,5 \pm 0,4$ & $9,1 \pm 0,9$ \\
\hline Ø желудя & & $11-18$ & $14,9 \pm 0,2$ & $6,5 \pm 0,8$ \\
\hline Ø плюски & & $10-16$ & $13,1 \pm 0,2$ & $7,6 \pm 0,9$ \\
\hline 1 плюски & & $5-10$ & $7,6 \pm 0,2$ & $9,4 \pm 1,1$ \\
\hline h плюски & & $3-7$ & $5,3 \pm 0,2$ & $12,3 \pm 1,3$ \\
\hline \multicolumn{5}{|c|}{ НПП «Святые горы» (естественная популяция) } \\
\hline L желудя & \multirow{5}{*}{47} & $22-30$ & $26,5 \pm 0,5$ & $9,2 \pm 1,3$ \\
\hline Ø желудя & & $10-18$ & $14,0 \pm 0,2$ & $7,2 \pm 0,7$ \\
\hline Ø плюски & & $10-14$ & $12,8 \pm 0,3$ & $8,1 \pm 1,3$ \\
\hline 1 плюски & & $5-10$ & $7,0 \pm 0,2$ & $9,9 \pm 1,1$ \\
\hline h плюски & & $3-6$ & $5,1 \pm 0,2$ & $12,2 \pm 0,9$ \\
\hline
\end{tabular}


ISSN 2077-1746. Вісник ОНУ. Біологія. 2017. Т. 22, вип. 2(41)

Продолжение таблицы 3

\begin{tabular}{|c|c|c|c|c|}
\hline 1 & 2 & 3 & 4 & 5 \\
\hline \multicolumn{5}{|c|}{ Заповедник «Меловая флора» (естественная популяция) } \\
\hline L желудя & \multirow{5}{*}{42} & $20-29$ & $25,7 \pm 0,3$ & $8,8 \pm 0,9$ \\
\hline Ø желудя & & $10-17$ & $13,9 \pm 0,2$ & $7,2 \pm 0,8$ \\
\hline Ø плюски & & $10-15$ & $12,5 \pm 0,3$ & $8,6 \pm 0,9$ \\
\hline 1 плюски & & $5-10$ & $7,0 \pm 0,2$ & $10,0 \pm 1,1$ \\
\hline h плюски & & $3-6$ & $5,1 \pm 0,2$ & $11,5 \pm 0,9$ \\
\hline \multicolumn{5}{|c|}{ РЛП «Клебан-бык» (естественная популяция) } \\
\hline L желудя & \multirow{5}{*}{57} & $22-33$ & $28,8 \pm 0,5$ & $9,9 \pm 1,5$ \\
\hline Ø желудя & & $12-17$ & $13,8 \pm 0,4$ & $8,9 \pm 1,1$ \\
\hline Ø плюски & & $11-15$ & $13,0 \pm 0,4$ & $8,5 \pm 1,3$ \\
\hline 1 плюски & & $5-10$ & $7,5 \pm 0,3$ & $9,4 \pm 1,4$ \\
\hline h плюски & & $4-6$ & $5,3 \pm 0,1$ & $12,8 \pm 0,7$ \\
\hline \multicolumn{5}{|c|}{ РЛП «Краматорский» (естественная популяция) } \\
\hline L желудя & \multirow{5}{*}{64} & $23-30$ & $27,0 \pm 0,6$ & $10,1 \pm 1,5$ \\
\hline Ø желудя & & $11-19$ & $14,3 \pm 0,5$ & $9,1 \pm 1,3$ \\
\hline Ø плюски & & $10-16$ & $12,9 \pm 0,4$ & $8,4 \pm 1,3$ \\
\hline 1 плюски & & $6-10$ & $7,3 \pm 0,3$ & $9,5 \pm 1,5$ \\
\hline h плюски & & $4-7$ & $5,2 \pm 0,1$ & $13,1 \pm 1,3$ \\
\hline \multicolumn{5}{|c|}{ Заказник «Великоанадольский лес» (искусственное насаждение) } \\
\hline L желудя & \multirow{5}{*}{75} & $23-39$ & $31,8 \pm 1,3$ & $10,3 \pm 1,4$ \\
\hline Ø желудя & & $13-21$ & $15,3 \pm 0,8$ & $8,3 \pm 0,9$ \\
\hline Ø плюски & & $12-18$ & $13,5 \pm 0,4$ & $8,5 \pm 0,9$ \\
\hline 1 плюски & & $7-12$ & $8,0 \pm 0,3$ & $13,3 \pm 1,5$ \\
\hline h плюски & & $4-8$ & $5,5 \pm 0,2$ & $16,3 \pm 1,9$ \\
\hline \multicolumn{5}{|c|}{ Заказник «Азовская дача» (искусственное насаждение) } \\
\hline L желудя & \multirow{5}{*}{43} & $24-33$ & $29,8 \pm 1,1$ & $9,4 \pm 1,6$ \\
\hline Ø желудя & & $13-20$ & $19,9 \pm 1,5$ & $11,2 \pm 1,5$ \\
\hline Ø плюски & & $11-17$ & $13,3 \pm 0,4$ & $7,3 \pm 1,7$ \\
\hline 1 плюски & & $7-11$ & $7,6 \pm 0,3$ & $11,2 \pm 1,1$ \\
\hline h плюски & & $4-7$ & $5,4 \pm 0,3$ & $15,1 \pm 0,7$ \\
\hline
\end{tabular}


Линейные размеры желудей в исследуемых районах произрастания Q. robur Донецкой области варьируют слабо. Так, их максимальная длина в исследуемых местопроизрастаниях превышает минимальную на 25-45 \%, по диаметру на 38-52 \%. Доминирующими оказались желуди средних ( $\mathrm{L}=25,1-30,0$ мм) и у больших размеров $(\mathrm{L}=35,1-35,0$ мм), что корреспондируется с результатами исследований, проведенными В. В. Кучеревским [30], которые составляли 60-80 \% от их общего числа в дубравах.

Установлено, что максимальный диаметр плюски на желудях превышает минимальный на 30-40 \%, высота плюски - на 40-60 \%, глубина плюски - на 35-65 \%. В насаждениях Донецкой области преобладают дубравы с узкими (Ø = 11-14 мм) и средними (Ø = 14-17 мм) плюсками на желудях [30], которые составляли 60-70 \% от их общего числа в исследуемых древостоях.

Отдельно стоит отметить значительное варьирование длины плодоноса у желудей $Q$. robur. Было выяснено, что максимальная длина плодоноса превышает минимальную в $1,2-5$ раз. Отмечено, что в районах произрастания НПП «Святые горы», заповедника «Меловая флора» и заказника «Великоанадольский лес» характерны плодоносы, длина которых равна половине кроющего листа (38-43 мм), а РЛП «Донецкий кряж», «Краматорский», «Клебан-бык» и заказника «Азовская дача» характеризуются плодоносами, длина которых значительно меньше половины кроющего листа (280-30 мм).

Важным аспектом лесовосстановительного процесса является урожайность. Согласно концепции, которую выдвинул И. И. Рац [11], по данным исследований 2014-2016 гг. обильной урожайностью (во все годы наблюдений) были отмечены пойменные дубравы НПП «Святые горы» и заповедник «Меловая флора» (табл. 4). Согласно шестибальной шкале Каппера [33], в исследуемых районах произрастания $Q$. robur были выявлены насаждения, набравшие 4 и 3 балла. Корреляционная связь между средней массой желудей соответствующих популяций и их урожайностью (по И. И. Рацу) четко не прослеживалась.

Так, например, в популяции НПП «Святые горы» при обильной урожайности выявлен наибольший результат по средней массе желудя (5,3 г). В заказнике «Азовская дача» удовлетворительная урожайность приводила к формированию желудей, которые по массе превосходят древостои с хорошей урожайностью.

Величина урожая желудей как количественное выражение плодоношения определяется в первую очередь условиями освещения, количеством тепла и влаги, соотношением этих показателей, почвенным плодородием, повреждаемостью желудей болезнями и насекомыми, наследственными особенностями деревьев $[9,18]$.

В отдельном взятом дубовом насаждении, оптимальные условия для плодоношения имеются при полноте верхнего яруса $0,6-0,7$ [24, 34]. Валовый урожай желудей увеличивается с уменьшением полноты яруса до предела $0,6[17$, $18,29]$. После этого, увеличение урожая на отдельных деревьях не компенсирует уменьшения количества плодоносящих деревьев на единице площади 
[24]. Снижение плодоношения с увеличением полноты насаждения следует объяснить комплексом причин, главные из которых: уменьшение поверхности и освещенности кроны, ослабление почвенного и воздушного питания плодоносящих деревьев. Важным моментом является то, что деревья $Q$. robur плодоносят, как правило, не ежегодно. В исследуемом регионе плодоношение отмечается приблизительно раз в 2-3 года $[23,34]$, что подтверждается результатами, полученными в 2014-2016 гг.

Таблица 4

Характеристика урожайности желудей и их массы в древостоях Quercus robur Донецкой области, 2014-2016 г.

\begin{tabular}{|c|c|c|}
\hline Macca 1000 штт., г & Урожайность по И. И. Рацу [11] & $\begin{array}{l}\text { Плодоношение и цветение } \\
\text { по В. Г. Капперу [33], балы }\end{array}$ \\
\hline \multicolumn{3}{|c|}{ РЛП «Донецкий кряж» } \\
\hline 3967 & Хорошая & 3 \\
\hline \multicolumn{3}{|c|}{ НПП «Святые горы» } \\
\hline 5321 & Обильная & 4 \\
\hline \multicolumn{3}{|c|}{ Заповедник «Меловая флора» } \\
\hline 3789 & Обильная & 4 \\
\hline \multicolumn{3}{|c|}{ РЛП «Клебан-бык» } \\
\hline 3107 & Удовлетворительная & 3 \\
\hline \multicolumn{3}{|c|}{ РЛП «Краматорский» } \\
\hline 2977 & Удовлетворительная & 3 \\
\hline \multicolumn{3}{|c|}{ Заказник «Великоанадольский лес» } \\
\hline 4926 & Хорошая & 4 \\
\hline \multicolumn{3}{|c|}{ Заказник «Азовская дача» } \\
\hline 4885 & Удовлетворительная & 3 \\
\hline
\end{tabular}

Различия между отдельными деревьями по форме желудей являются вполне определенными и дают возможность легко различать желуди рядом стоящих деревьев по следующим размерам плодов: крупно-, средне-, мелкоплодные. Выделяются деревья с продолговатыми, укороченными округлыми желудями и типичными (обыкновенными) желудями. Форма желудей у отдельных деревьев весьма устойчива по годам и общие размеры желудей несколько изменяются $[21,24]$. Данный аспект свидетельствует о генетической предопределенности исследуемых морфологических признаков желудей. Полученная в 
исследованиях группировка желудей, ранжированных по форме и размерам приведена в таблице 5.

Формовое разнообразие желудей в древостоях Quercus robur

в Донецкой области

\begin{tabular}{|c|c|c|c|}
\hline $\begin{array}{c}\text { Отношение L/Ø } \\
\text { желудя }\end{array}$ & $\begin{array}{c}\text { Отношение Ø/L } \\
\text { желудя }\end{array}$ & $\begin{array}{c}\text { Преобладающая форма (по } \\
\text { А. С. Яковлеву [24]) }\end{array}$ & $\begin{array}{c}\text { Преобладающая крупность } \\
\text { (по М Д Данилову [7]) }\end{array}$ \\
\hline \multicolumn{4}{|c|}{ РЛП «Донецкий кряж» } \\
\hline 1,9 & 0,52 & Типичная & Среднеплодная \\
\hline \multicolumn{4}{|c|}{ НПП «Святые горы» } \\
\hline 1,89 & 0,53 & Типичная & Крупноплодная \\
\hline \multicolumn{4}{|c|}{ Заповедник «Меловая флора» } \\
\hline 1,84 & 0,54 & Типичная & Среднеплодная \\
\hline \multicolumn{4}{|c|}{ РЛП «Клебан-бык» } \\
\hline 2,1 & 0,48 & Длинноплодная & Среднеплодная \\
\hline \multicolumn{4}{|c|}{ РЛП «Краматорский» } \\
\hline 1,88 & 0,53 & Типичная & Среднеплодная \\
\hline \multicolumn{4}{|c|}{ Заказник «Великоанадольский лес» } \\
\hline 2,1 & 0,48 & Длинноплодная & Крупноплодная \\
\hline \multicolumn{4}{|c|}{ Заказник «Азовская дача» } \\
\hline 1,49 & 0,66 & Широкоокруглая & Крупноплодная \\
\hline
\end{tabular}

Дискуссионным вопросом в селекции $Q$. robur является зависимость между размерами и массой желудей с одной стороны, и ростом дубов, выращенных из них, с другой. В большинстве исследований указывается на существенное влияние массы желудей на рост $Q$. robur до 39 лет [12], результаты других наблюдений указывают, что рост дуба из крупных и мелких желудей нивелируется на 2-3-й год [29]. В исследованиях С. А. Крюковой, В. К. Ширина [12] отмечено, что в большинстве случаев желуди плюсовых деревьев меньше по размерам и массе, чем у среднестатистических по показателям роста растений. Такой факт свидетельствует о том, что ориентация на крупные желуди при закладке насаждений может привести к обеднению генетического разнообразия будущих дубрав.

Многими авторами отмечалось, что более стабильным признаком в урожайные годы являлся коэффициент формы желудей, т. е. соотношение меж- 
ду диаметром и длиной $[12,24]$. В четырех популяциях $Q$. robur в Донецкой области преобладают деревья с типичной формой желудей, в двух дубравах доминируют растения с длинноплодной формой плода, и лишь в одной популяции - преобладают деревья с широкоокруглой формой желудей (табл. 5).

Крупные желуди встречаются в 3-х древостоях, а для остальных четырех свойственны средние размеры плодов. Выявлено, что растения с ранними сроками распускания листьев дают обильный урожай (популяции НПП «Святые горы» и заповедник «Меловая флора»).

Полученные данные указывают на зависимость размеров и массы желудей $Q$. robur от многих факторов, а также генетических особенностей деревьев. Максимальные различия между насаждениями $Q$. robur одного выдела обнаружены в пойменных дубравах. У дубов, удаленных друг от друга на 50 м, масса желудей различалась в 3-5 раз. Также отмечено, что дубравы пойменного экотипа раноцветущей формы плодоносят чаще и обильнее по сравнению с нагорными дубравами позднецветущей формы.

\section{Выводы}

1. В пяти природных популяциях $Q$. robur и двух популяциях искусственного происхождения на заповедных территориях в Донецкой области в ходе трехлетних фенологических наблюдений выявлено две формы дубов - ранняя и поздняя, различающиеся по срокам цветения и распускания листьев.

2. Q. robur не отличался стабильной урожайностью желудей. В каждом древостое присутствовали дубы, которые не давали урожай в годы наблюдений. В Донецкой области межурожайный период составлял 2-3 года. На урожайность влияли полнота и бонитет насаждений, возраст и индивидуальные особенности плодоносящих деревьев. Лучшей урожайностью обладали раннераспускающиеся деревья, приуроченные к пойменным экотипам.

3. Уровень изменчивости морфологических параметров желудей колебался в пределах 8-10\%, уровень изменчивости желудей по массе - 30-45 \%. По форме желуди в пределах древостоя практически не изменялись и стабильно сохраняли коэффициент формы в урожаях разных лет. У дубрав, произрастающих в пойменных экотипах, были отмечены наиболее крупные желуди.

4. $\quad$ В древостоях Q. robur в Донецкой области преобладали желуди типичной формы и средней крупности. Чем южнее насаждение Q. robur, тем большая встречаемость длинноплодных и широкоокруглых форм желудей дуба.

Статья поступила в редакцию 24.08.2017

\section{Список использованной литературы}

1. Смирнова О. В. Популяционная парадигма в экологии и экосистемные процессы / О. В. Смирнова // Бюл. МОИП. Отд. биол. - 2011. - Т. 116. - № 4. - С. 41-47.

2. Евстигнеев О. И. Отношение лиственных деревьев к свету / О. И. Евстигнеев // Биол. науки. - 1991. T. 8. - № 332. - C. 20-29. 
3. Рябцев И. С. Особенности возобновления широколиственных пород в байрачном лесу (на примере участка «Острасьевы яры» государственного природного заповедника «Белогорье») / И. С. Рябцев, И. М. Рябцева, М. Ю. Тиходеева // Вестник Санкт-Петербургского университета. Серия 3. Биология. 2011. - № 1. - C. 13-26

4. Грищенко К. К. Демографическая структура ценопопуляций видов-эдификаторов производных липовых и кленовых лесов в Саратовском правобережье / К. К. Грищенко: автореф. дис. ... канд. биол. наук. - Саратов, 2008. - $20 \mathrm{c}$.

5. Смирнова О. В. Ценопопуляционный анализ и прогнозы развития дубово-грабовых лесов Украины О. В. Смирнова, А. А. Чистякова, Т. И. Дробышева // Журн. общей биологии. - 1987. - Т. 48, № 2. С. 200-212

6. Лосицкий К. Б. Восстановление дубрав / К. Б. Лосицкий. - М.: Сельхозгиз, 1963. - 359 с.

7. Данилов М. Д. Разнообразие дуба черешчатого по размерам и морфологическим особенностям желудей в условиях северо-восточной границы его ареала / М. Д. Данилов // Сб. трудов Поволж. Лесотехн. ин-та им. М. Горького. - Йошкар-Ола, 1967. - Вып. 3. - № 58. - С. 163-178.

8. Кирюков Ю. Л. Плодоношение дуба / Ю. Л. Кирюков, К. В. Крыжановский // Шипов лес. Лесоводственно-хозяйственная характеристика и обзор научных работ (к 60-летию опытного дела в массиве). Воронеж: ВГУ, 1969. - С. 129-143.

9. Данилов М. Д. Некоторые особенности структуры популяций дуба черешчатого в условиях северо-восточной части его ареала / М. Д. Данилов, В. Д. Гурьев, П. Н. Федоров // Закономерности внутривидовой изменчивости лиственных древесных пород. - Свердловск, (УНЦ АН СССР). - 1975. - С. $13-17$.

10. Гурьев Д. Г. Формовое разнообразие дуба черешчатого в лесах Чувашской АССР / Д. Г. Гурьев. - Автореф. дисс. . канд. биол. Наук. - Йошкар-Ола. - 1972. - 20 с.

11. Рац И. И. Шкала урожайности лиственных пород / И. И. Рац // Лесное хоз-во. - 1938. - №. 1. - С. 7.

12. Крюкова С. А. Плодоношение дубрав и плюсовіх деревьев дуба черешчатого / С. А. Крюкова, В. К. Ширин //Лесотехнический журнал. - 2016. - Т. 6. - №. 2 (22). - С. 22-30

13. Демаков Ю. П. Динамика урожайности желудей дуба / Ю. П. Демаков, А. В. Исаев // Научные труды государственного природного заповедника «Большая Кокшага». - 2011. - № 5. - С. 144-158.

14. Маленко А. А. К вопросу о выращивании дуба черешчатого в сухой степи (Алтайский край) / А. А. Маленко, Е. С. Ширяева // Вестник Алтайского государственного аграрного университета. - 2013. - № 8 (106). - C. 55-58

15. Овчаренко А. А. Влияние засухи на урожайность дубовых насаждений Востока Саратовской области $/$ А. А. Овчаренко, А. М. Кузьмичёв // Вестник Тамбовского университета. Серия: Естественные и технические науки. - 2012. - Т. 17. - № 6. - С. 1575-1576.

16. Передельский Н. А. Влияние аэротехногенного загрязнения на плодоношение дубовых древостоев / Н А. Передельский // Актуальные проблемы лесного комплекса. Майкоп. - 2007. - № 19. - С. 4.

17. Major S. Variability of Quercus robur L. and Quercus petraea (Matt.) Liebl. acorn size in the region of the Pomeranian plains / S. Major // Dendrobiology. - 2002. - T. 47. - pp. 25-31

18. Демаков Ю. П. Информативность морфометрических параметров деревьев, желудей и листьев дуба черешчатого (Quercus robur L.) в географических культурах / Ю. П. Демаков, В. Г. Краснов, С. В. Кириллов, М. И. Смышляева, А. В. Антропова // Вестник Поволжского государственного технологического университета. Серия: Лес. Экология. Природопользование. - 2015. - № 3 (27). - С. 18-33.

19. Смышляева М. И. Особенности плодоношения дуба черешчатого (Quercus robur L.) в географических культурах/ М. И. Смышляева, В. Г. Краснов, С. В. Кириллов // Актуальные направления научных исследований XXI века: теория и практика. - 2015. - Т. 3. - № 5-4. - С. 259-264.

20. Соломаха Н. Г. Відновлення штучних дібров на ДП «Маріупольська ЛНДС» / Н. Г. Соломаха. - 2008. С. $139-144$.

21. Кириллов С. В. Рост лесных культур дуба черешчатого, созданных разными формами желудей С. В. Кириллов // Известия высших учебных заведений. Лесной журнал. - 2013. - № 4 (334). - С. 4.

22. Бородавка В. А. Великоанадоль: насущные уроки эффективного лесоразведения в сухой степи / В. А. Бородавка, Д. А. Добрынин, Н. М. Шматков // Примеры зарубежного опыта устойчивого лесоуправления и лесопользования: сб. статей под общ. ред. Н. Шматкова. - Всемирный фонд дикой природы (WWF).- M. - 2012. - C. 139-154.

23. Бородавка В. А. Перспективы сохранения и восстановления естественных лесов в региональных ландшафтных парках Донецкого кряжа / В. А. Бородавка, Е. Б. Бородавка // Актуальные проблемы лесного комплекса. - 2010. - № 25. - С. 5.

24. Яковлев А. С. Дубравы Среднего Поволжья / А. С. Яковлев, А. С. Яковлев // Йошкар-Ола: МарГТУ. 1999. $-326 \mathrm{c}$ 
25. Короткова Т. Н. Современное состояние лесных насаждений регионального ландшафтного парка „Клебан-Бык” / Т. Н. Короткова, Н. Г. Соломаха // Актуальные проблемы лесного комплекса. - 2010. № $25 .-5 \mathrm{c}$.

26. Булыгин Н. Е. Дендрология. Фенологические наблюдения над лиственными древесными растениями / Н. Е. Булыгин. - Пособие по проведению учеб.-науч. исследований для студентов лесохоз. фак. - Л.: РИОЛТА, 1976. - 70 c.

27. Полякова Л. В. Сравнительный биохимический анализ многовековых деревьев и 55-летних культур дуба черешчатого, произрастающих на территории НПП «Святые горы» / Л. В. Полякова, С. Г. Гамаюнова, П. Т. Журова // Журнал Лесоведение - 2012. - С. 173-180.

28. Полякова Л. В. Биохимические особенности суховершинных деревьев дуба черешчатого / Л. В. Полякова, С. Г. Гамаюнова, П. Т. Журова, В. И. Литвиненко // Журнал Лесоведение. - 2015. - № 4. - С. $28-35$.

29. Askeyev O. V. The effect of climate on the phenology, acorn crop and radial increment of pedunculate oak (Quercus robur) in the middle Volga region, Tatarstan, Russia / O. V. Askeyev // International journal of biometeorology. - 2005. - Т. 49. - № 4. - С. 262-266.

30. Кучеревский В. В. Внутривидовая изменчивость и формовое разнообразие дуба обыкновенного в условиях юго-востока Украины: дис. ... кандидата с.-х. наук : 03.00 .05 / В. В. Кучеревский. - Донецк, 1988. $19 \mathrm{c}$.

31. Barzdajn W. The variability of dimensions of Quercus robur L. and Q. petraea [Matt.] Liebl. acorns in Poland / W. Barzdajn // Dendrobiology. - 2002. - 47. - P. 21-24.

32. Barzdajn W. Preliminary results of an experiment with Polish provenances of pedunculate oak (Quercus robur L) and sessile oak (Q. petraea [Matt] Liebl) / W. Barzdajn // Annales des sciences forestières. - EDP Sciences. - 1993. - Vol. 50. - P. 222-227.

33. Денеко В. Н. Учет урожая лесных семян. Методические указания к проведению практического занятия для студентов ЛХФ очной и заочной форм обучения, специальность 250201 «Лесное дело» / В. Н. Денеко, А. В. Капралов, Л. Л. Садриева // Екатеринбург. - 2012. - 14 с.

34. Семериков Л. Ф. Популяционная структура древесных растений: на примере видов дуба Европейской части СССР и Кавказа / Л. Ф. Семериков. - Наука, 1986. - 140 с.

35. Слєпих О. О. Ритм розвитку та розповсюдження фенологічних форм дуба черешчатого (Quercus robur L.) у Донецькій області / О. О. Слєпих // Науковий вісник Чернівецького університету. Біологія (Біологічні системи). -2016. - Т. 8, Вип. 2. - С. 272-279.

Статья поступила в редакцию 06.09.2017

\section{О. О. Слєпих, І. І. Коршиков}

Донецький ботанічний сад НАН України, вул. Маршака, 50, м. Кривий Ріг, 50089, Україна

\section{ПЛОДОНОШЕННЯ ДУБА ТА ФОРМОВЕ РІЗНОМАНІТТЯ ЖОЛУДІВ ДУБА ЧЕРЕШЧАТОГО (QUERCUS ROBUR L.) В ПРИРОДНИХ ТА ШТУЧНИХ ДІБРОВАХ ПІВДЕННОГО СХОДУ УКРАЇНИ}

\section{Резюме}

Проблема. В останні десятиліття відзначена деградація і масове всихання дібров у багатьох європейських країнах. Популяції Q. robur в Донецькій області знаходяться на південному кордоні природного поширення. Для них виражене всихання дібров, яке викликане недостатньою кількістю вологи, шкідниками і хворобами, надлишковим рекреаційним навантаженням і недотриманням правил догляду за лісом. Незадовільне відновлення дібров пов'язано, в першу чергу, з недостатністю в них високоякісних жолудів, які потребують ефективної селекції. 
Мета. Провести аналіз мінливості жолудів $Q$. robur в Донецькій області за морфометричними ознаками, плодоношенням, врожайності i формовому різноманіттю.

Матеріали і методи. Матеріалом для дослідження були плоди Q. robur, взяті з семи популяцій. Мінливість морфометричних характеристик жолудів проводили згідно з рекомендаціями В. В. Кучеревського. Оцінка цвітіння і плодоношення проводилася за шестибальною шкалою В. Г. Каппера. Урожайність визначали за шкалою врожайності листяних порід I. І. Раца.

Результати та висновки. Рівень мінливості морфологічних параметрів жолудів у досліджуваному регіоні коливався в межах 8-16\%, рівень мінливості жолудів за масою - 30-45 \%. За плодоношенням дуба в досліджуваному регіоні встановлено, що його 2 популяції мають рясне плодоношення, 2 - добре і 3 - задовільне. У Донецькій області міжврожайний період становить 2-3 роки. У деревостанах $Q$. robur переважають жолуді типової форми і середньої крупності. Чим південніше насадження $Q$. robur, тим більша зустрічальність довгоплідних і широкоокруглих форм жолудів дуба. Кращим урожаєм і великими морфометричними параметрами плодів характеризувались популяції, які виростали в заплавних екосистемах і мали ранню фенологічний форму.

Ключові слова: Посушливість; зростання; фенологічна форма; мінливість; врожайність; крупність плода; коефіцієнт форми плода.

\author{
A. A. Slepykh, I. I. Korshikov \\ Donetsk Botanical Garden under NAS of Ukraine, Marshak str., 50, Kryvii Rig, \\ 50089, Ukraine
}

\title{
FRUCTIFICATION AND FORM DIVERSITY OF PETIOLATE OAK (QUERCUS ROBUR L.) OF THE NATURAL AND ARTIFICIAL SOUTH EAST OAK WOODS OF UKRAINE
}

\begin{abstract}
Introduction. In recent decades, degradation and mass drying of oak forests to a greater or lesser degree have been observed in many European countries. Populations of $Q$. robur in the Donetsk region are on the southern border of natural distribution, in which drying of oak forests caused by a lack of moisture, pests and diseases, excessive recreational load and non-observance of the rules of silvicultural care is clearly expressed. First and foremost, this unsatisfactory resumption of oak forests is due to the shortage in them of high-quality acorns, which require efficient selection. Purpose. To analyze the variability of acorns according to the morphometric features, determine fructification of oaks, level of harvest of oaks and variety of shape of the Q. robur acorns, which grow on the southern border of the range of natural distribution in the Donetsk region.

Material and Methods. The material for research was acorns of $Q$. robur, taken from seven populations. The variability of the morphometric characteristics of acorns was carried out according to the recommendations by V.V. Kucherevsky. Evaluation of flowering and fructification of oaks was performed on a six-point Kapper scale. The level of harvest of oaks was determined on the basis of the Ratz scale of hardwood productivity.
\end{abstract}


Results and conclusions. The level of variability of the morphological parameters of the acorns in the region under study varies between $8-16 \%$, the level of variability of acorns by weight is 30-45\%. According to the fructification of oaks in the investigated region it has been revealed: two populations have abundant fructification, in 2 populations fructification is good and in 3 populations - satisfactory. Inter-harvest period amounted to 2-3 years in the Donetsk region. In the stands of $Q$. robur in the Donetsk region, acorns of typical shape and medium size predominate. The closer $Q$. robur stands grow to the south, the greater the occurrence of long-fruited and wide-rounded forms of acorns of the oaks is. The better harvest and largest morphometric parameters of oak acorns were in populations that have grown in floodplain ecosystems and have an early phenological form.

Key words: Arid conditions; growth; phenological form; variability; yield; fruit size; shape of the fruit.

\section{References}

1. Smirnova O. V. (2011) Population paradigm in ecology and ecosystem processes [Populyacionnaya paradigma v ehkologii i ehkosistemnye process]. Byul. MOIP. Otd. biol. T. 116, № 4, pp. 41-47.

2. Evstigneev O. I. (1991) The ratio of deciduous trees to light [Otnoshenie listvennyh derev'ev k svetu]. Biol. nauki, T. 8, № 332, pp. 20-29

3. Ryabcev I. S. (2011) Peculiarities of the renewal of broad-leaved species in the birch forest (on the example of the "Ostravaevy Yar" section of the state nature reserve "Belogorye") [Osobennosti vozobnovleniya shirokolistvennyh porod v bajrachnom lesu (na primere uchastka «Ostras'evy yary» gosudarstvennogo prirodnogo zapovednika «Belogor'e»)]/ Ryabcev I. S., Ryabceva I. M., Tihodeeva M. YU. // Vestnik Sankt-Peterburgskogo universiteta. Seriya 3. Biologiya.- №. 1. - pp. 13-26

4. Grishchenko K. K. (2008) Demographic structure of cenopopulations of species-edificators of derivatives of lime and maple forests in the Saratov right bank [Demograficheskaya struktura cenopopulyacij vidov-ehdifikatorov proizvodnyh lipovyh i klenovyh lesov v Saratovskom pravoberezh'e] avtoref. dis. ... kand. biol. nauk. Saratov $-20 \mathrm{p}$

5. Smirnova O. V., CHistyakova A. A., Drobysheva T. I (1987) Cenopopulation analysis and forecasts of oak and hornbeam forests development in Ukraine [Cenopopulyacionnyj analiz i prognozy razvitiya dubovo-grabovyh lesov Ukrainy. ZHurn. obshchej biologii. T. 48, № 2. pp. 200-212

6. Losickij K. B. (1963) Restoration of oak groves [Vosstanovlenie dubrav], M.: Sel'hozgiz, 359 p.

7. Danilov M. D. (1967) The diversity of oak in the size and morphological features of acorns in the conditions of the northeastern border of its range [Raznoobrazie duba chereshchatogo po razmeram i morfologicheskim osobennostyam zheludej v usloviyah severo-vostochnoj granicy ego areala], Sb. trudov Povolzh. Lesotekhn. in-ta im. M. Gor'kogo, Joshkar-Ola Vyp. 3, № 58, pp. 163-178.

8. Kiryukov Yu. L., Kryzhanovskij K. V. (1969) Fruiting of oak [Plodonoshenie duba], SHipov les. Lesovodstvenno-hozyajstvennaya harakteristika i obzor nauchnyh rabot (k 60-letiyu opytnogo dela v massive), Voronezh: VGU, pp. 129-143.

9. Danilov M. D., Gur'ev V. D., Fedorov P. N. (1975) Some peculiarities of the structure of the populations of oak conifers in the conditions of the northeastern part of its range [Nekotorye osobennosti struktury populyacij duba chereshchatogo v usloviyah severovostochnoj chasti ego areala], Zakonomernosti vnutrividovoj izmenchivosti listvennyh drevesnyh porod, Sverdlovsk, (UNC AN SSSR), pp. 13-17.

10. Gur'ev D. G. (1972) Form diversity of oak tree in the forests of the Chuvash Autonomous Republic [Formovoe raznoobrazie duba chereshchatogo v lesah CHuvashskoj ASSR]. Avtoref. diss. . kand. biol. nauk- Joshkar-Ola, $20 \mathrm{p}$.

11. Rac I. I. (1938) Scale of productivity of hardwoods [Shkala urozhajnosti listvennyh porod], Lesnoe hoz-vo, №. 1, p. 7.

12. Kryukova S. A., SHirin V. K. (2016) Fruiting of oak trees and plus trees of oak tree [Plodonoshenie dubrav i plyusovih derev’ev duba chereshchatogo], Lesotekhnicheskij zhurnal, T. 6, №. 2 (22), pp. $22-30$.

13. Demakov Yu. P., Isaev A. V. (2011) Dynamics of productivity of acorns of an oak [Dinamika urozhajnosti zheludej duba], Nauchnyie trudyi gosudarstvennogo prirodnogo zapovednika «Bolshaya Kokshaga», №. 5, pp. $144-158$ 
14. Malenko A. A., SHiryaeva E. S. (2013) On the issue of growing oak trees in the dry steppe (Altai Territory) [K voprosu o vyrashchivanii duba chereshchatogo v suhoj stepi (Altajskij kraj)], Vestnik Altajskogo gosudarstvennogo agrarnogo universiteta, №. 8 (106), pp. 55 -58.

15. Ovcharenko A. A., Kuz'michyov A. M. (2012) Effect of drought on productivity of oak plantings in the East of the Saratov region [Vliyanie zasuhi na urozhajnost' dubovyh nasazhdenij Vostoka Saratovskoj oblasti], Vestnik Tambovskogo universiteta. Seriya: Estestvennye i tekhnicheskie nauki, T. 17, №. 6, pp. 1575 -1576.

16. Peredel'skij N. A. (2007) Influence of aerotechnogenic pollution on the fruiting of oak stands [Vliyanie aehrotekhnogennogo zagryazneniya na plodonoshenie dubovyh drevostoev], Aktual'nye problemy lesnogo kompleksa, Majkop, №. 19, 4 p.

17. Major S. (2002) Variability of Quercus robur L. and Quercus petraea (Matt.) Liebl. acorn size in the region of the Pomeranian plains, Dendrobiology, T. 47, pp 25-31

18. Demakov Yu. P., Krasnov V. G., Kirillov S. V., Smyshlyaeva M. I., Antropova A. V. (2015) Informativity of morphometric parameters of trees, acorns and leaves of oak quiver (Quercus robur L.) in geographical cultures [Informativnost' morfometricheskih parametrov derev'ev, zheludej i list'ev duba chereshchatogo (Quercus robur L.) v geograficheskih kul'turah], Vestnik Povolzhskogo gosudarstvennogo tekhnologicheskogo universiteta. Seriya: Les. EHkologiya. Prirodopol'zovanie, №. 3 (27)., pp. 18-33

19. Smyshlyaeva M. I.? Krasnov V. G., Kirillov S. V. (2015) Specific features of fructification of oak conifers (Quercus robur L.) in geographic cultures [Osobennosti plodonosheniya duba chereshchatogo (Quercus robur L.) v geograficheskih kul'turah], Aktualnyie napravleniya nauchnyih issledovaniy XXI veka: teoriya i praktika, T. 3., №. 5-4, pp 259-264.

20. Solomaha N. G. (2008) Restoration of artificial gills at SE "Mariupol LNDS". [Vidnovlennya shtuchnih dibroy na DP «Mariupol's'ka LNDS»], pp. 139-144

21. Kirillov S. V. (2013) Growth of forest cultures of oak stems, created by different forms of acorns [Rost lesnyh kul'tur duba chereshchatogo, sozdannyh raznymi formami zheludej], Izvestiya vysshih uchebnyh zavedenij. Lesnoj zhurnal, №. 4 (334), pp,4.

22. Borodavka V. A., Dobrynin D. A., SHmatkov N. M. (2012) Velikoanadol: Essential lessons of effective afforestation in the dry steppe [Velikoanadol': nasushchnye uroki ehffektivnogo lesorazvedeniya v suhoj stepi], Primery zarubezhnogo opyta ustojchivogo lesoupravleniya i lesopol'zovaniya: sb. statej pod obshch. red. N. SHmatkova//Vsemirnyj fond dikoj prirody (WWF), pp. 139-154.

23. Borodavka V. A., Borodavka E. B. (2010) Prospects for the conservation and restoration of natural forests in the regional landscape parks of the Donetsk ridge [Perspektivy sohraneniya i vosstanovleniya estestvennyh lesov v regional'nyh landshaftnyh parkah Doneckogo kryazha], Aktual'nye problemy lesnogo kompleksa, №. 25,5 p.

24. Yakovlev A. S., Yakovlev I. A. (1999) The oak forests of the Middle Volga region [Dubravy Srednego Povolzh’ya], Joshkar-Ola: MarGTU, 326 p.

25. Korotkova T. N., Solomaha N. G. (2010) The current state of forest plantations of the regional landscape park "Kleban- Byk" [Sovremennoe sostoyanie lesnyh nasazhdenij regional'nogo landshaftnogo parka „KlebanByk”], Aktual’nye problemy lesnogo kompleksa, №. 25, 5 p.

26. Bulygin N. E. (1976) Dendrology. Phenological observations of deciduous woody plants [Dendrologiya. Fenologicheskie nablyudeniya nad listvennymi drevesnymi rasteniyami]: Posobie po provedeniyu ucheb. - nauch. issledovanij dlya studentov lesohoz. Fak, L.: RIOLTA, 70 p.

27. Polyakova L.V., Gamayunova S. G., ZHurova P. T. (2012) Comparative biochemical analyzes of centuries-old trees and 55-year-old cultures of oak crooked, growing on the territory of Scientific-Production Enterprise «Svyatye gory» [Sravnitel'nyj biohimicheskij analitz mnogovekovyh derev'ev i 55-letnih kul'tur duba chereshchatogo, proizrastayushchih na territorii NPP «Svyatye gory».], pp. $173-180$.

28. Polyakova L. V., Gamayunova, S. G., ZHurova, P. T. Litvinenko V. I. (2015) Biochemical features of the oak peaks of the oak tree [Biohimicheskie osobennosti suhovershinnyh derev'ev duba chereshchatogo], Lesovedenie, №. 4, pp. 28-35.

29. Askeyev O. V. (2005) The effect of climate on the phenology, acorn crop and radial increment of pedunculate oak (Quercus robur) in the middle Volga region, Tatarstan, Russia, International journal of biometeorology, $\mathrm{T}$. 49, №. 4, pp. 262-266

30. Kucherevskij V. V. (1988) Intraspecific variability and mold variety of common oak in the south-east of Ukraine [Vnutrividovaya izmenchivost' i formovoe raznoobrazie duba obyknovennogo $\mathrm{v}$ usloviyah yugo-vostoka Ukrainy]: dis. ... kandidata s.-h. nauk: 03.00.05, Doneck, 19 p.

31. Barzdajn W. (2002) The variability of dimensions of Quercus robur L. and Q. petraea [Matt.] Liebl. acorns in Poland. Dendrobiology, 47, pp. 21-24. 
32. Barzdajn W. (1993) Preliminary results of an experiment with Polish provenances of pedunculate oak (Quercus robur $\mathrm{L}$ ) and sessile oak ( $Q$ petraea [Matt] Liebl) //annales des sciences forestières, EDP Sciences, T. 50, pp. 222-227.

33. Deneko V. N., Kapralov A. V., Sadrieva L. L. (2012) Accounting for harvest of forest seeds. Methodical instructions for conducting a practical lesson for students. [Uchet urozhaya lesnyh semyan. Metodicheskie ukazaniya $\mathrm{k}$ provedeniyu prakticheskogo zanyatiya dlya studentov LHF ochnoj i zaochnoj form obucheniya, special'nost' 250201 «Lesnoe delo»], Ekaterinburg - 14 p.

34. Semerikov L. F. (1986) Population structure of woody plants: on the example of species of oak in the European part of the USSR and the Caucasus [Populyacionnaya struktura drevesnyh rastenij: na primere vidov duba Evropejskoj chasti SSSR i Kavkaza], Nauka, 140 p.

35. Slepyh O.O. (2016) Rhythm of development and distribution of phenological forms of oak (Quercus robur L.) in Donetsk region [Ritm rozvitku ta rozpovsyudzhennya fenologichnih form duba chereshchatogo (Quercus robur L.) u Donec'kij oblasti]. Naukovij visnik CHernivec'kogo universitetu. Biologiya (Biologichni sistemi), T. 8, Vip. 2, pp. $272-279$. 